\title{
Antihistaminergic and Anticholinergic Properties of the Root Bark Aqueous Extract of Diospyros mespiliformis (Ebenaceae) on Hypersecretion of Gastric Acid Induced in Wistar Rats
}

\author{
Vandza Luc Vandi, ${ }^{1}$ André Perfusion Amang ${ }^{1},{ }^{1}$ Christophe Mezui, ${ }^{2}$ \\ Gaël Tchokomeni Siwe $\mathbb{D}^{3}{ }^{3}$ Gustave Lebeau Otto Ndji, ${ }^{4}$ Hacheked Mbida, ${ }^{1}$ Odile Baponwa, ${ }^{1}$ \\ and Paul Vernyuy Tan (D) $^{3}$ \\ ${ }^{1}$ Department of Biological Sciences, Faculty of Science, University of Maroua, P.O. Box 814, Maroua, Cameroon \\ ${ }^{2}$ Department of Biological Sciences, Higher Teachers' Training College, University of Yaoundé I, P.O. Box 047, \\ Yaoundé, Cameroon \\ ${ }^{3}$ Department of Animal Biology and Physiology, Faculty of Science, University of Yaoundé I, P.O. Box 812, Yaoundé, Cameroon \\ ${ }^{4}$ Department of Life Science, Higher Teachers' Training College, University of Ngaoundéré, P.O. Box 652, Bertoua, Cameroon
}

Correspondence should be addressed to André Perfusion Amang; perfusionamang@yahoo.fr

Received 23 September 2021; Accepted 10 January 2022; Published 31 January 2022

Academic Editor: Smail Aazza

Copyright ( $) 2022$ Vandza Luc Vandi et al. This is an open access article distributed under the Creative Commons Attribution License, which permits unrestricted use, distribution, and reproduction in any medium, provided the original work is properly cited.

\begin{abstract}
Objective. The objective of this study was to elucidate the antisecretory mechanism of the root bark aqueous extract of Diospyros mespiliformis (RBAEDM) in Wistar rats. Materials and methods. RBAEDM was tested on three experimental animal models of gastric acid hypersecretion including pyloric ligation (PL), PL with histamine, and carbachol pretreatments. The ulcerated surface, mucus mass, $\mathrm{pH}$, gastric acidity, and pepsin activity were determined. Some bioactive compounds revealed by qualitative phytochemistry were quantified. Some markers of oxidative stress in vivo such as malondialdehyde (MDA), superoxide dismutase (SOD), catalase (CAT), reduced glutathione (GSH), and in vitro antioxidant tests (ABTS: 2,2' -azinobis-3-ethylbenzothiazoline-6sulfonic acid, DPPH: 2,2-diphenyl-2-picrylhydrazyl, and FRAP: ferric reducing antioxidant power) were determined. Results. In the three models studied, RBAEDM resulted in increases in the percentages of inhibition ranging from 9.50 to $59.52 \%$ of gastric ulcer and mucus mass. This increase was accompanied by the reduction in acidity and pepsin activity. The administration of RBAEDM resulted in a significant decrease $(p<0.05, p<0.01)$ in MDA levels correlated with a significant increase $(p<0.05$, $p<0.01)$ in CAT and nitrite levels compared with the negative control. RBAEDM has the ability to scavenge ABTS and DPPH radicals and to reduce FRAP, and the inhibitory concentration of $50 \%\left(\mathrm{IC}_{50}\right)$ of the ABTS radical was $220 \mu \mathrm{g} / \mathrm{mL}$ compared with the butylhydroxytoluene (BHT) control $(175 \mu \mathrm{g} / \mathrm{mL})$. Quantitative phytochemistry revealed abundant polyphenols, flavonoids, tannins, saponins, and anthocyanin. Conclusion. RBAEDM protected gastric mucous membrane for gastric acid by mechanisms that would involve both anticholinergic and antihistaminergic pathways.
\end{abstract}

\section{Introduction}

Stress, whether psychological, physical, or physiological, is a highly plausible factor in the development of ulcer disease and is associated with increased morbidity and mortality $[1,2]$. Psychological distress is generally correlated with the genesis of gastric ulcers and affects all individuals regardless of their status $[2,3]$. Stress induces ulcers through several pathophysiological mechanisms including gastric acid secretion by stimulation of the vagus nerve and ischaemia resulting from hypersecretion of catecholamines [4, 5]. Indeed, vagus nerve stimulation leads to gastric acid secretion, which activates pepsin and produces free radicals such as the superoxide anion, hydrogen peroxide, and hydroxyl radicals. The increased production of the latter causes lipid peroxidation and consequently gastric lesions $[3,5,6]$. Hypersecretion of catecholamines resulting from the activation of the sympathetic-adrenal-medullary axis 
contributes to ischaemia of the gastric mucosa following vasoconstriction [1]. However, the body possesses its own means of defense such as mucus and bicarbonate secretion, increased activity of antioxidant enzymes, and nitrogen monoxide (NO) synthesis.

The first line of gastric mucosal defense consists of the mucus and bicarbonate barrier. The secretion of bicarbonate into the mucus gel layer is essential to maintain a $\mathrm{pH}$ gradient at the epithelial surface, which represents a line of defense against gastric acid $[7,8]$.

The vasodilating effect of $\mathrm{NO}$ contributes in maintaining the integrity of the gastric mucosal barrier [9] through the action of the constituent NO synthase (cNOS). It degrades into nitrite $\left(\mathrm{NO}_{2}^{-}\right)$and then nitrate $\left(\mathrm{NO}_{3}\right)$. $\mathrm{NO}$ is a molecule with a half-life of a few seconds released by vascular endothelial cells. It is synthesized in response to various substances such as histamine and acetylcholine [10]. In the gastrointestinal tract, the NO produced diffuses rapidly into the tissues, where it activates guanylate cyclase, which converts GTP into cyclic GMP. This leads to a decrease in $\mathrm{Ca}^{2+}$ concentration and induces relaxation of the smooth muscle and an increase in blood flow [10].

The conventional treatment used for the prevention and healing of stress-induced ulcers is the intake of antisecretory agents such as anticholinergics (verapamil), $\mathrm{H}_{2}$ receptor antagonists (ranitidine), proton-pump inhibitors (omeprazole), and antacids (sodium bicarbonate). However, these antisecretory agents have many side effects, including diarrhoea, nausea, constipation, and headache [11]. Hence, the use of phytotherapy is the alternative route for the treatment of gastric ulcers.

Diospyros mespiliformis is a plant of the Ebenaceae family used in ethnomedicine for the treatment of ulcers, diarrhoea, malaria, and fever [12]. In addition, its numerous pharmacological properties such as its analgesic and antiinflammatory [13], antibacterial [14], antiseptic [15], and gastroprotective [16] activities have been demonstrated. However, its antisecretory activity had not yet been studied; hence, the objective of this work was to determine the antisecretory activity and mechanism of action of RBAEDM against gastric ulcers induced by pyloric ligation in rats.

\section{Materials and Methods}

2.1. Animal Material. Male albino Wistar rats, $12 \pm 2$ weeks old and weighing 160 to 200 grams, were used. These animals were bred in the animal house of the Laboratory of Animal Physiology and Pharmacognosy of the University of Maroua. They were fed a standard laboratory diet with the following composition: maize meal (50\%), soybean meal (20\%), fish meal $(15 \%)$, bone meal $(4 \%)$, vitamin complex $(0.1 \%)$, cottonseed cake $(10 \%)$, palm oil $(0.1 \%)$, and cooking salt $(0.8 \%)$ with unrestricted access to tap water.

2.2. Plant Material. The mature adult plants were collected in the forest. The mature root bark of Diospyros mespiliformis depth at $10 \mathrm{~cm}$ was harvested in the Mokolo locality, Far North of Cameroon (N10 44'12.93072";
E13 $47^{\prime} 3.74784^{\prime \prime}$; latitude: 10.73693). The plant was authenticated at the Herbarium Faun School of Garoua in comparison with the existing specimen (No. HEFG/01404). After harvesting, the root barks of $D$. mespiliformis were shade-dried and powdered for extract preparation.

2.3. Preparation of RBAEDM. Three hundred grams (300 g) of powder was macerated in 3 liters of distilled water for 24 hours. After filtration using Whatman Paper No. 3, the solution was evaporated in an oven at $50^{\circ} \mathrm{C}$, resulting in $12 \mathrm{~g}$ of extract ( $4 \%$ yield). The resulting extract was stored at $4^{\circ} \mathrm{C}$ for further use.

2.4. Reagents. Pepsin, histamine, carbachol, $\mathrm{NaNO}_{2}, \mathrm{BSA}$, $\mathrm{NAOH}$, naphthylenediamine (NED), sulfamide, ABTS, $\mathrm{DPPH}$, and FRAP are purchased from Sigma Chemical and Sigma-Aldrich Chemie (USA, Germany, India).

\subsection{Quantitative Phytochemical Analysis of RBAEDM}

2.5.1. Dosage of Total Phenolic Compounds. The protocol of [17] was used to determine the level of phenolic compounds in the extract. The absorbance was read at $750 \mathrm{~nm}$ with a spectrophotometer. The concentration of phenolic compounds was calculated from the regression equation of the gallic acid calibration curve $(0-250 \mu \mathrm{g} / \mathrm{mL})$ and expressed in milligram equivalents of gallic acid per hundred grams of crude extract (mEqGA/100g dry matter).

2.5.2. Dosage of Flavonoids. The total flavonoid content of the extract was determined using the aluminum chloride colorimetric method [18]. The absorbance was measured with a spectrophotometer at $415 \mathrm{~nm}$. The total flavonoid content was calculated using the quercetin calibration curve $(0-250 \mu \mathrm{g} / \mathrm{mL})$, and the results were expressed as milligram quercetin equivalents per hundred grams of extract (mEqQ/100g dry matter).

2.5.3. Dosage of Tannin. The tannin content was measured by the Folin-Ciocalteu method described by [19]. The absorbance was measured with a spectrophotometer at $700 \mathrm{~nm}$. A calibration curve was plotted using tannic acid $(0-250 \mu \mathrm{g} / \mathrm{mL})$, and the results were expressed in milligram equivalents of tannic acid per hundred grams of extract (mEqTA/100g dry matter).

2.5.4. Dosage of Saponins. The quantification of saponins was carried out using the method described by [20]. The absorbance was measured with a spectrophotometer at $530 \mathrm{~nm}$. A calibration curve was drawn using galactose $(0-250 \mu \mathrm{g} / \mathrm{mL})$, and the results were expressed in milligram galactose equivalents per hundred grams of extract (mEqG/ $100 \mathrm{~g}$ dry matter).

2.5.5. Dosage of Anthocyanins. The total anthocyanin content was determined using the $\mathrm{pH}$ differential method described by [21]. The absorbance was measured with a 
spectrophotometer at 520 and $700 \mathrm{~nm}$ at $\mathrm{pH} 1.0$ and 4.5, respectively.

2.6. Antisecretory Screening of RBAEDM. For antisecretory screening, the method described by [22] was used to induce gastric ulcers. After a 48-hour non-hydric fasting, 30 rats were divided into 6 groups (1 normal control, 1 negative control, 1 positive control, and 3 test groups) of 5 rats each. These animals received distilled water $(5 \mathrm{~mL} / \mathrm{kg})$ for the normal and negative controls, ranitidine $(50 \mathrm{mg} / \mathrm{kg}$ ) for the positive control, and extract $(100,200$, and $400 \mathrm{mg} / \mathrm{kg}$ ) for the test groups. The doses of extract were chosen based on the previous work [16]. One hour after administration of respective treatments, all the animals except normal control underwent a laparotomy performed under anesthesia using ketamine $(50 \mathrm{mg} / \mathrm{mL})$ at dose of $2 \mathrm{~mL} / \mathrm{kg}$ of body weight by intraperitoneal route and associated diazepam $(5 \mathrm{mg} / \mathrm{mL})$ at dose of $5 \mathrm{mg} / \mathrm{kg}$. The stomach was ligated at the level of the pyloric sphincter and was carefully replaced into the abdomen, which was then sutured. The animals were deprived of water during the postoperative period. Six (6) hours after ligation, they were again subjected to diazepam/ ketamine anesthesia and sacrificed. Stomach was removed from the abdominal cavity, and the gastric content of each rat was collected in dry tubes. The content was centrifuged at $2000 \mathrm{rpm}$ for 10 minutes, the supernatant was collected, and its volume was measured. The gastric juice obtained was used immediately for $\mathrm{pH}$ determination and acid titration. Ulcerations were measured lenghtwise and widthwise, and their surface is calculated accordingly for score attribution as described below. The mucus produced in each stomach was carefully scraped off with a microscope slide and weighed on a precision electronic balance. Stomach homogenates $(20 \%)$ were prepared using phosphate-buffered saline (PBS) for the determination of oxidative stress parameters in vivo. The two most active doses during the pyloric ligation test were chosen for antihistaminergic and anticholinergic studies.

2.7. Antihistaminergic Activity of RBAEDM. For antihistaminergic activity, the protocol described by [4] was used. Twenty rats were divided into 4 groups of 5 rats each. The positive and negative controls were given ranitidine $(50 \mathrm{mg} / \mathrm{kg})$ and distilled water $(5 \mathrm{~mL} / \mathrm{kg})$ per os, respectively. The test groups received extract at 200 and $400 \mathrm{mg} / \mathrm{kg}$. Thirty (30) minutes after their respective treatments, pyloric ligation was performed as described by [22]. Histamine $(2.5 \mathrm{mg} / \mathrm{kg})$ was administered subcutaneously one hour after pyloric ligation. Four hours after histamine injection, all the animals were sacrificed, the remaining protocol being the same as described for antisecretory screening.

2.8. Anticholinergic Activity of RBAEDM. The protocol was the same as described for antihistaminergic activity with the difference that the positive control group received verapamil $(50 \mathrm{mg} / \mathrm{kg})$ instead of ranitidine and histamine that were replaced by carbachol $(1 \mathrm{mg} / \mathrm{kg})$ in all groups.
2.9. Ulcerated Surface and Ulcer Index. Ulcerated surface and ulcer index were calculated as described by Tan et al. [23] Ulcerated surface: length $x$ width. Ulcer scores were allotted as follows: no ulcer $=0.0$; ulcer surface $\leq 0.5 \mathrm{~mm}^{2}=1$; ulcer surface $>0.5 \leq 2.5 \mathrm{~mm}^{2}=2$; ulcer surface $>2.5 \leq 5 \mathrm{~mm}^{2}=3$; ulcer surface $>5 \leq 10 \mathrm{~mm}^{2}=4$; ulcer surface $>10 \leq 15 \mathrm{~mm}^{2}=5$; ulcer surface $>15 \leq 20 \mathrm{~mm}^{2}=6$; ulcer surface $>20 \leq 25 \mathrm{~mm}^{2}=7$; ulcer surface $>25 \leq 30 \mathrm{~mm}^{2}=8$; ulcer surface $>30 \leq 35 \mathrm{~mm}^{2}=9$; and ulcer surface $>35 \mathrm{~mm}^{2}=10$. The ulcer index (UI) was calculated with the following formula:

$$
\mathrm{UI}=\frac{1}{n} \sum_{1}^{n} \text { score } \pm \mathrm{SEM} .
$$

2.10. $p H$ Measurement and Acidity Titration of RBAEDM. The $\mathrm{pH}$ was determined using a $\mathrm{pH}$ meter. The gastric acidity was measured using the colorimetric titration method by adding two drops of phenolphthalein with the $\mathrm{NaOH}$ solution $(0.1 \mathrm{~N})$ until the pink coloration was obtained. The volume of $\mathrm{NaOH}$ used was recorded to determine the acidity.

2.11. Determination of Pepsin Activity of RBAEDM. The determination of the hydrolytic activity of pepsin was performed by incubating $1 \mathrm{~mL}$ of gastric juice in $2 \mathrm{~mL}$ bovine serum albumin (BSA) $(50 \mathrm{mg} / \mathrm{mL})$ at $37^{\circ} \mathrm{C}$ for $10 \mathrm{~min}$ [24].

2.12. In Vivo Antioxidant Activity of RBEADM on Pyloric Ligature. In vivo antioxidant capacity of the extract was evaluated in the stomach homogenates. The determination of total protein was done according to the Biuret method [24] and that of the MDA level was done according to the protocol of Wilbur et al. [25]. The activity of superoxide dismutase (SOD), CAT, and reduced glutathione (GSH) was determined according to the protocol of Misra and Fridovich, Sinha, and Ellman [26-28], respectively.

2.13. Determination of Nitrite. Nitrite in stomach homogenates was measured with the Griess reagent according to the method described by [29]. The chromophore absorption during nitrite deionization with sulfanilamide coupled to naphthylenediamine (NED) was read at $546 \mathrm{~nm}$. The product obtained was proportional to the amount of nitrite present in the sample. The nitric oxide level was determined from the calibration curve established from different concentrations of $\mathrm{NaNO}_{2}$.

2.14. Antiradical Activity of the ABTS Extract. The free radical activity of ABTS (2,2' -azinobis-3-ethylbenzothiazoline-6-sulfonic acid) was measured according to the method described by [30]. Fifty microliters $(50 \mathrm{~mL})$ of extract or standard was added to $150 \mu \mathrm{L}$ of $\mathrm{ABTS}^{+}(7 \mathrm{mM})$, and the mixture was stirred and incubated at room temperature for $40 \mathrm{~min}$. The absorbance was read with a spectrophotometer at $745 \mathrm{~nm}$. The antioxidant capacity of the sample was 
determined from the calibration curve established with Trolox $(0-125 \mu \mathrm{g} / \mathrm{mL})$. The inhibition percentage was calculated using the following formula: $I \%=((\mathrm{Ac}-\mathrm{At}) / \mathrm{Ac})-$ 100 with (Ac: absorbance of the control, At: absorbance of the test). From this percentage, the concentration of extract inhibiting $50 \%\left(\mathrm{IC}_{50}\right)$ of the ABTS radical was determined.

2.15. Evaluation of the Antiradical Activity of the Extract with $D P P H$. This method is based on the measurement of antioxidant ability to trap the DPPH radical [31]. The antioxidant capacity of samples was determined from the calibration range established with the Trolox $(0-125 \mu \mathrm{g} / \mathrm{mL})$.

2.16. FRAP Assay. The reducing capacity of the extract was determined according to the method described by Benzie and Strain [32]. The absorbance of the reaction medium was determined at $593 \mathrm{~nm}$. An increase in absorbance corresponded to an increase in the reducing capacity of the tested extract. The reducing capacity of the sample was determined from a calibration range established with vitamin $\mathrm{C}$ $(0-125 \mu \mathrm{g} / \mathrm{mL})$.

2.17. Statistical Analysis. The data were analyzed using GraphPad Prism 5.03 software. Statistical analysis was performed by the one-way analysis of variance (ANOVA) followed by the Newman-Keuls posttest. The values were expressed as mean \pm standard error to the mean (SEM). $p$ values $<0.05$ were considered statistically significant.

\section{Results}

3.1. Quantitative Phytochemical Analysis of RBAEDM. The results in Table 1 reveal the presence in RBAEDM of a quantity of certain bioactive compounds (polyphenols (86.58); flavonoids (55.22); tannins (21.71); anthocyanins (10.14); and saponins (21.92) (mEq/100g of dry)).

\subsection{Effect of RBAEDM on Acid Secretion and Gastric Ulcers} Induced by Pyloric Ligation. Macroscopic observation of the stomach following pyloric ligation in rats shows lesions in the form of red bands on the glandular part of the stomach (Figure 1). Photograph A shows normal healthy mucosa (normal control). The ulcerated surface is larger in the negative control (Photograph B: $22.40 \mathrm{~mm}^{2}$ ) and decreases significantly in animals treated with the extract at doses of 100, 200, and $400 \mathrm{mg} / \mathrm{kg}$ (Photograph C: 5.60; Photograph D: 8.80 ; and Photograph E: $7.60 \mathrm{~mm}^{2}$, respectively). Pyloric ligation decreases significantly $(p<0.01)$ the mucus production in the negative control compared with that in the normal control. The treatment with the extract $(100,200$, and $400 \mathrm{mg} / \mathrm{kg}$ ) significantly increased the mucus production in a dose-dependent manner $(34.48 ; 38.64$; and $65.30 \mathrm{mg}$ ) compared with the negative control $(28.28 \mathrm{mg})$ (Table 2). Gastric acidity decreased significantly $(p<0.05)$ at 100 and $400 \mathrm{mg} / \mathrm{kg}$ (5.20 and $4.80 \mathrm{mEq} / \mathrm{L}$, respectively) of extract compared with the negative control $(8.40 \mathrm{mEq} / \mathrm{L})$ (Table 3$)$.
3.3. Effect of RBAEDM on Gastric Acid Secretion and Gastric Ulcers Induced by Association between Pyloric Ligation and Histamine. The following photographs show the lesions of the gastric mucosa induced by the combination of pyloric ligation and histamine, and these appear as dark red bands (Figure 2). No lesion was observed in the normal control (Photograph A). The surface of these lesions is larger in the negative control (Photograph B: $28.40 \mathrm{~mm}^{2}$ ); this decreases significantly in animals treated at a dose of 200 and $400 \mathrm{mg} / \mathrm{kg}$ of extract and ranitidine (Photograph C: 22.20; Photograph D: 3.60; and Photograph E: $12.40 \mathrm{~mm}^{2}$, respectively). This decrease in ulcerated surface area is correlated with a significant $(p<0.01)$ increase in mucus production $(78 \mathrm{mg})$ and a significant $(p<0.05)$ decrease in acidity $(13.20 \mathrm{mEq} / \mathrm{L})$ at the dose of $400 \mathrm{mg} / \mathrm{kg}$ compared with the negative control (48.02 $\mathrm{mg}$ and $24.40 \mathrm{mEq} / \mathrm{L}$, respectively) (Tables 4 and 5). The percentage inhibition of pepsin activity increased by 38.79 and $43.10 \%$ at 200 and $400 \mathrm{mg} / \mathrm{kg}$ extract, respectively.

3.4. Effect of RBAEDM on Gastric Acid Secretion and Gastric Ulcers Induced by Pyloric Ligation Combined with Carbachol. Figure 3 shows stomach ulcerated by pyloric ligation combined with carbachol. The stomach wall of normal control does not show any ulcer (Photograph A). It can be seen that the surface area of these lesions is larger in the negative control (Photograph B: $22.60 \mathrm{~mm}^{2}$ ) and decreases in animals treated with the extract at doses of 200 and $400 \mathrm{mg} / \mathrm{kg}$ and verapamil (Photograph C: 8.80; Photograph D: 7.40; and Photograph E: $12.20 \mathrm{~mm}^{2}$, respectively). The treatment with RBEADM (200 and $400 \mathrm{mg} / \mathrm{kg}$ ) significantly increased $(p<0.001)$ the mucus production $(77.30$ and $84.48 \mathrm{mg})$ and significantly decreased $(p<0.01)$ gastric acidity compared with the negative control ( $35.84 \mathrm{mg}$ and 30 $\mathrm{mEq} / \mathrm{L}$, respectively) (Tables 6 and 7). Percentage inhibition of pepsin activity increased by 32.52 and $34.94 \%$ at 200 and $400 \mathrm{mg} / \mathrm{kg}$.

3.5. Effect of RBAEDM on Some Oxidative Stress Parameters and Nitrites. Table 8 shows the effect of the aqueous extract on some parameters of oxidative stress. It shows a significant increase $(p<0.05)$ in the MDA level in the negative control compared with that in the normal control. On the other hand, the treatment with RBAEDM resulted in a significant decrease $(p<0.05 ; p<0.01)$ in MDA levels in the extracttreated groups compared with that in the negative control. This decrease in MDA concentration correlates with a significant $(p<0.05 ; p<0.01)$ increase in catalase activity. There was a significant $\left(p^{<} 0.001\right)$ and dose-dependent increase in the level of nitrite in stomach tissues at different doses of the extract.

3.6. In Vitro Antioxidant Effect of RBAEDM. In vitro antioxidant results show that the root bark aqueous extract of Diospyros mespiliformis has the ability to trap $77.7 \%$ of ABTS and $68.57 \%$ of DPPH and to reduce iron by $58.33 \%$ (Table 9). The concentrations of RBEADM inhibiting $50 \%\left(\mathrm{IC}_{50}\right)$ of the ABTS, DPPH radical, and FRAP were 220,494 , and $543 \mu \mathrm{g} / \mathrm{mL}$, 
TABLE 1: Quantitative phytochemical analysis of RBAEDM.

\begin{tabular}{lcccc}
\hline $\begin{array}{l}\text { Polyphenols } \\
(\mathrm{mEqAG} / 100 \mathrm{~g})\end{array}$ & $\begin{array}{c}\text { Flavonoids } \\
(\mathrm{mEqQu} / 100 \mathrm{~g})\end{array}$ & $\begin{array}{c}\text { Tannins } \\
(\mathrm{mEqCa} / 100 \mathrm{~g})\end{array}$ & $\begin{array}{c}\text { Anthocyanins } \\
(\mathrm{mEqCy}-3-\mathrm{G} / 100 \mathrm{~g})\end{array}$ & $\begin{array}{c}\text { Saponins } \\
(\mathrm{mEqG} / 100 \mathrm{~g})\end{array}$ \\
\hline $86.58 \pm 0.73$ & $55.22 \pm 0.83$ & $21.71 \pm 0.20$ & $10.14 \pm 0.57$ & $21.92 \pm 0.35$ \\
\hline
\end{tabular}

mEqAG: milliequivalent gram of gallic acid, mgEqQu: milliequivalent gram of quercetin, mEqCa: milliequivalent gram of catechin, mEqCy-3-G: milliequivalent gram of cyanidin-3-glucoside, and mEqG: milliequivalent gram of galactose.

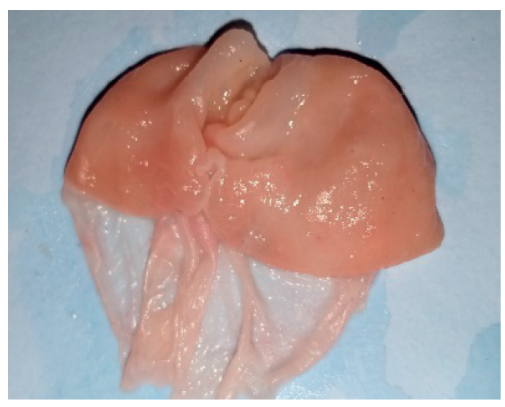

(a)

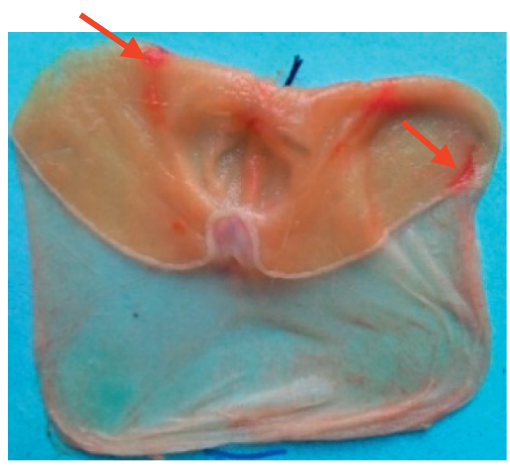

(d)

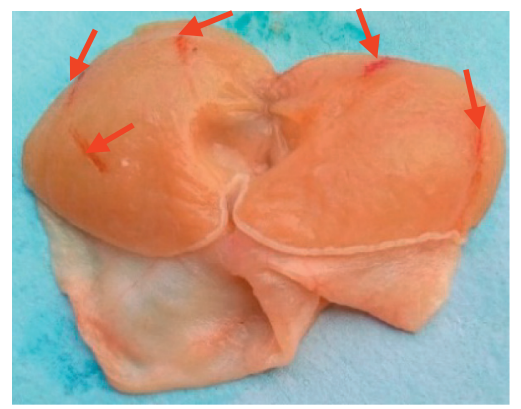

(b)

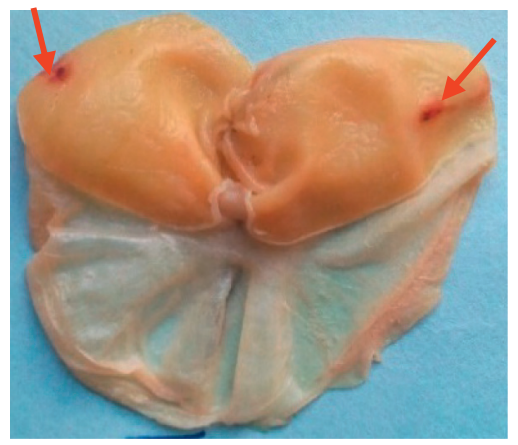

(e)

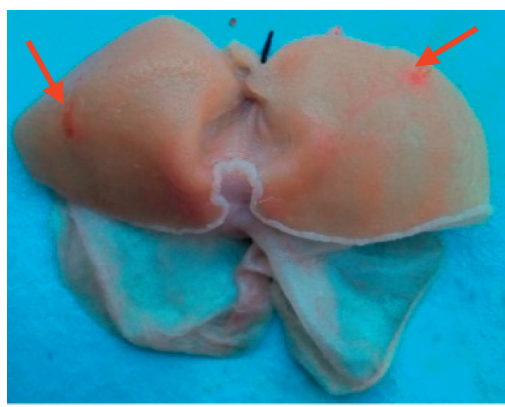

(c)

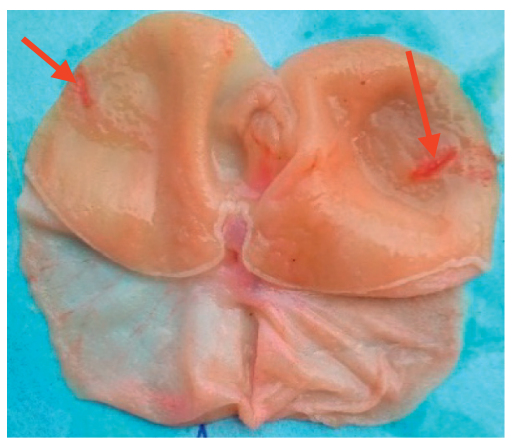

(f)

FIGURE 1: Photograph of stomach ulcerated by pyloric ligation. (a) Normal control; (b) negative control; (c) $100 \mathrm{mg} / \mathrm{kg}$ of RBAEDM; (d) $200 \mathrm{mg} / \mathrm{kg}$ of RBAEDM; (e) $400 \mathrm{mg} / \mathrm{kg}$ of RBAEDM; and (f) $50 \mathrm{mg} / \mathrm{kg}$ of ranitidine; $\rightarrow$ : indications of gastric lesions.

TABLE 2: Effect of RBAEDM on ulcers induced by pyloric ligation.

\begin{tabular}{lccccc}
\hline Treatments & Dose $(\mathrm{mg} / \mathrm{kg})$ & Ulcerated surface $\left(\mathrm{mm}^{2}\right)$ & Ulcer index & Inhibition $(\%)$ & Mucus mass $(\mathrm{mg})$ \\
\hline Normal control & - & - & - & - & $42.67 \pm 2.25$ \\
Negative control & - & $22.40 \pm 5.53$ & $4.24 \pm 0.51$ & - & $28.28 \pm 1.52^{\# \#}$ \\
RBAEDM & 100 & $5.60 \pm 0.81^{* *}$ & $2.56 \pm 0.19$ & 39.62 & $34.48 \pm 2.23$ \\
RBAEDM & 200 & $8.80 \pm 2.63^{*}$ & $3.00 \pm 0.75$ & 29.24 & $38.64 \pm 2.83^{*}$ \\
RBAEDM & 400 & $7.60 \pm 2.94^{*}$ & $2.35 \pm 0.58$ & 44.57 & $65.30 \pm 3.83^{* * *}$ \\
Ranitidine & 50 & $8.00 \pm 1.30^{*}$ & $2.78 \pm 0.34$ & 34.43 & $34.12 \pm 1.62$ \\
\hline
\end{tabular}

$N=5$ : number of animals per group. Values are expressed as mean \pm standard error of the mean; RBAEDM: root bark aqueous extract of Diospyros mespiliformis; ${ }^{*} p<0.05,{ }^{* *} p<0.01$, and ${ }^{* * *} p<0.001$ : significantly different compared with the negative control; ${ }^{\# \#} p<0.01$ : significantly different compared with the normal control.

respectively, compared with the butylhydroxytoluene (BHT) control of $175 \mu \mathrm{g} / \mathrm{mL}$ (Table 9).

\section{Discussion}

Gastric ulcer can be caused by gastric acid hypersecretion [33]. Acid hypersecretion can result either from stimulation of histamine, gastrin, and acetylcholine receptors, or from uncontrolled production of gastrin in the case of Zollinger-Ellison syndrome [34]. In this work, hypersecretion was induced by pyloric ligation and by the combination of pyloric ligation with histamine and then carbachol.

Pyloric ligation induces basal acid secretion and was performed for antisecretory screening purpose. Accumulation of acid in the stomach is the cause of lesions. In fact, hydrochloric acid $(\mathrm{HCl})$ causes lesions either by direct irritation of the stomach membrane cells that cause stomach membrane necrosis or by activating the conversion of pepsinogen into pepsin, which is a proteolytic enzyme that destroys membrane proteins $[4,35]$. In addition, pyloric 
TABLE 3: Effect of RBAEDM on gastric acid secretion induced by pyloric ligation.

\begin{tabular}{lcccc}
\hline Treatments & Dose $(\mathrm{mg} / \mathrm{kg})$ & $\mathrm{VGJ}(\mathrm{mL})$ & $\mathrm{pH}$ & Gastric acidity $(\mathrm{mEq} / \mathrm{L})$ \\
\hline Normal control & - & - & - & - \\
Negative control & - & $1.92 \pm 0.19$ & $2.46 \pm 0.15$ & $7.76 \pm 0.14$ \\
RBAEDM & 100 & $1.28 \pm 0.21^{*}$ & $3.69 \pm 0.37^{*}$ & $4.48 \pm 0.42^{*}$ \\
RBAEDM & 200 & $0.84 \pm 0.09^{* * *}$ & $4.38 \pm 0.09^{* *}$ & $4.32 \pm 0.42^{*}$ \\
RBAEDM & 400 & $0.66 \pm 0.08^{* * *}$ & $4.25 \pm 0.32^{* *}$ & $4.00 \pm 0.50^{*}$ \\
Ranitidine & 50 & $0.67 \pm 0.13^{* * *}$ & $6.08 \pm 0.54^{* * *}$ & $6.16 \pm 1.55$ \\
\hline
\end{tabular}

$N=5$ : number of animals per group. Values are expressed as mean \pm standard error of the mean; RBAEDM: root bark aqueous extract of Diospyros mespiliformis; VGJ: volume of gastric juice; ${ }^{*} p<0.05,{ }^{* *} p<0.01$, and ${ }^{* * *} p<0.001$ : significantly different compared with the negative control.

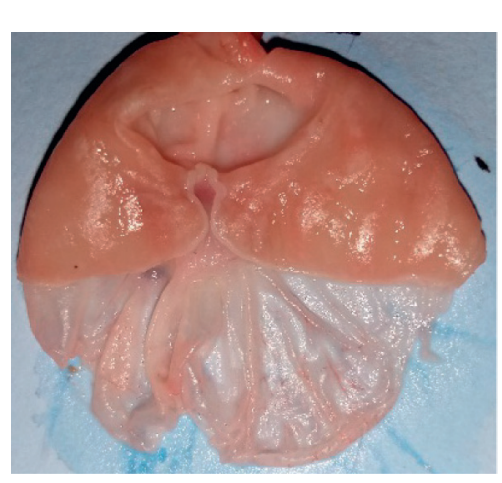

(a)

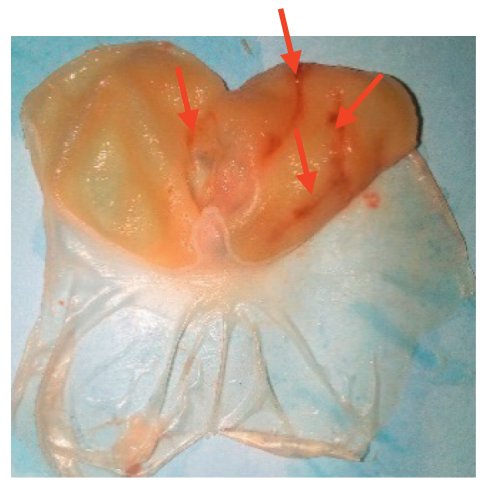

(b)

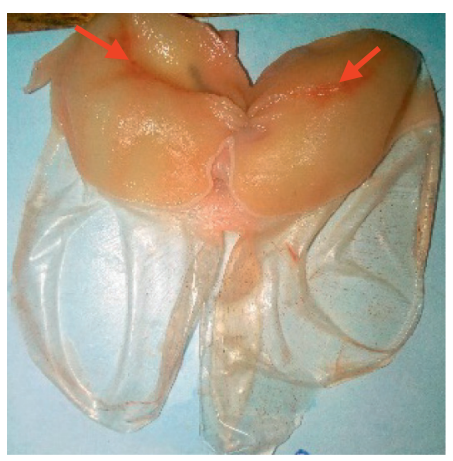

(c)

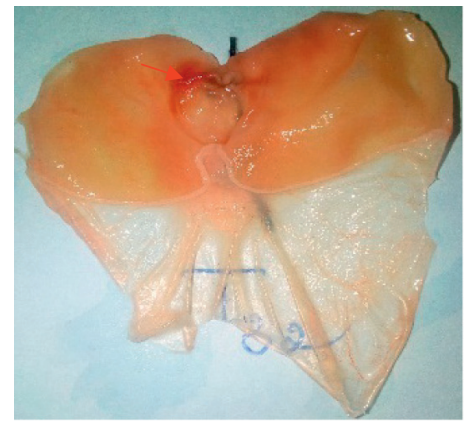

(d)

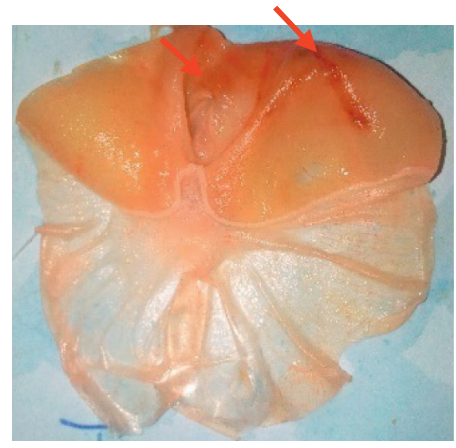

(e)

Figure 2: Photograph of stomach ulcerated by pyloric ligation combined with histamine. (a) Normal control; (b) negative control; (c) $200 \mathrm{mg} / \mathrm{kg}$ of RBAEDM; (d) $400 \mathrm{mg} / \mathrm{kg}$ of RBAEDM; and (e) $50 \mathrm{mg} / \mathrm{kg}$ of ranitidine; $\rightarrow$ : indications of gastric lesions.

ligation and laparotomy also induce stress, which contributes to acid secretion, thus aggravating the gastric mucosa damaging. RBAEDM significantly and dose-dependently decreased gastric acidity at all doses compared with the negative control. This decrease in acidity was correlated with a significant increase in $\mathrm{pH}$ at different doses of the extract compared with the negative control. These results would suggest that RBAEDM possesses an antisecretory activity. The work of [36] showed that the reduction in gastric acidity by the aqueous extract of Corchorus olitorius could involve either direct inhibition of acid secretion or a simple neutralization of the acid secreted by the parietal cells, hence the interest in exploring its antisecretory mechanism of action.

Elucidation of antisecretory mechanisms has been carried out using pyloric ligation associated with histamine and carbachol. Indeed, histamine is an agonist of the $\mathrm{H}_{2}$ receptors of parietal cells of the stomach. Histamine binding to the $\mathrm{H}_{2}$ receptors activates adenylate cyclase, leading to the synthesis of cAMP. The latter will phosphorylate the $\mathrm{H}^{+} / \mathrm{K}^{+} /$ ATPase pump and consequently stimulate the secretion of gastric acid [37]. Carbachol is a cholinergic receptor agonist, which binds to the muscarinic type 3 receptors $\left(M_{3}\right)$. This binding activates phospholipase $\mathrm{C}$, which catalyzes the synthesis of phosphatidylinositol triphosphate $\left(\mathrm{IP}_{3}\right)$ and diacylglycerol (DAG), which causes an increase in the concentration of cytosolic calcium [33] and consequently leads to the phosphorylation of the $\mathrm{H}^{+} / \mathrm{K}^{+}$/ATPase pump and thus the secretion of gastric acid. Chemical agents that decrease gastric acid secretion via blockade of $\mathrm{H}_{2}$ and $\mathrm{M}_{3}$ receptors are important in the treatment of gastric ulcers involving gastric acid hypersecretion [38]. Thus, receptor antagonists such as ranitidine and verapamil block their receptors and therefore cause non-phosphorylation of the $\mathrm{H}^{+} / \mathrm{K}^{+} /$ATPase pump. The subcutaneous injection of 
TABLE 4: Effect of RBAEDM on PL-induced ulcers combined with histamine.

\begin{tabular}{lccccc}
\hline Treatments & Dose $(\mathrm{mg} / \mathrm{kg})$ & Ulcerated surface $\left(\mathrm{mm}^{2}\right)$ & Ulcer index & Inhibition $(\%)$ & Mucus mass $(\mathrm{mg})$ \\
\hline Normal control & - & - & - & - & $42.67 \pm 2.25$ \\
Negative control & - & $28.40 \pm 2.46$ & $4.63 \pm 0.18$ & - & $48.02 \pm 3.60$ \\
RBAEDM & 200 & $20.20 \pm 1.39^{* *}$ & $4.19 \pm 0.13^{* *}$ & 9.50 & $49.14 \pm 3.79$ \\
RBAEDM & 400 & $3.60 \pm 1.50^{* * *}$ & $2.20 \pm 0.20^{* * *}$ & 52.48 & $72.63 \pm 2.65^{* *}$ \\
Ranitidine & 50 & $12.40 \pm 1.36^{* * *}$ & $3.23 \pm 0.34^{* *}$ & 30.23 & $46.86 \pm 6.82$ \\
\hline
\end{tabular}

$N=5$ : number of animals per group. Values are expressed as mean \pm standard error of the mean; RBAEDM: root bark aqueous extract of Diospyros mespiliformis; ${ }^{* *} p<0.01$ and ${ }^{* * *} p<0.001$ : significantly different compared with the negative control.

TABLE 5: Gastric acid hypersecretion induced by pyloric ligation combined with histamine.

\begin{tabular}{lcccc}
\hline Treatments & Dose $(\mathrm{mg} / \mathrm{kg})$ & VGJ $(\mathrm{mL})$ & $\mathrm{pH}$ & Gastric acidity $(\mathrm{mEq} / \mathrm{L})$ \\
\hline Normal control & - & - & - & - \\
Negative control & - & $2.68 \pm 0.53$ & $2.70 \pm 0.37$ & $24.40 \pm 2.92$ \\
RBAEDM & 200 & $0.90 \pm 0.40^{*}$ & $4.40 \pm 0.88$ & $15.60 \pm 2.40$ \\
RBAEDM & 400 & $0.64 \pm 0.18^{* *}$ & $5.81 \pm 0.51^{* *}$ & $13.20 \pm 3.00^{*}$ \\
Ranitidine & 50 & $1.58 \pm 0.22^{*}$ & $2.55 \pm 0.18$ & $19.60 \pm 1.60$ \\
\hline
\end{tabular}

$N=5$ : number of animals per group. Values are expressed as mean \pm standard error of the mean; RBAEDM: root bark aqueous extract of Diospyros mespiliformis; VGJ: volume of gastric juice, IPA: inhibition of pepsin activity; ${ }^{*} p<0.05$ and ${ }^{* *} p<0.01$ : significantly different compared with the negative control.

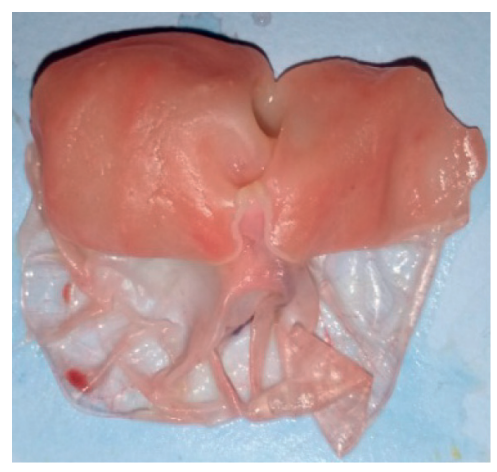

(a)

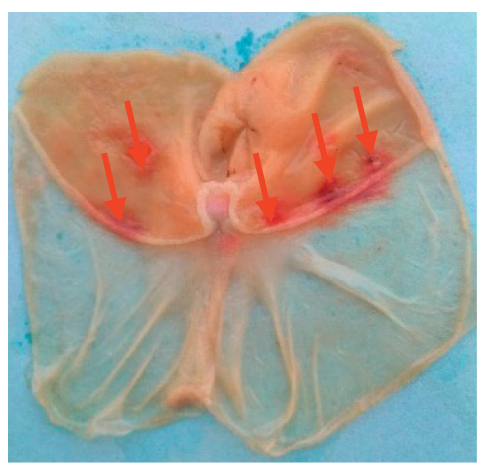

(b)

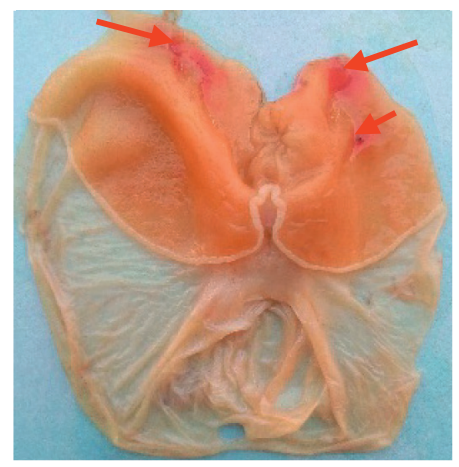

(c)

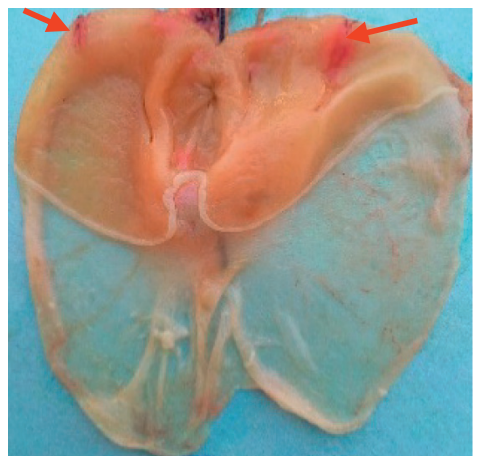

(d)

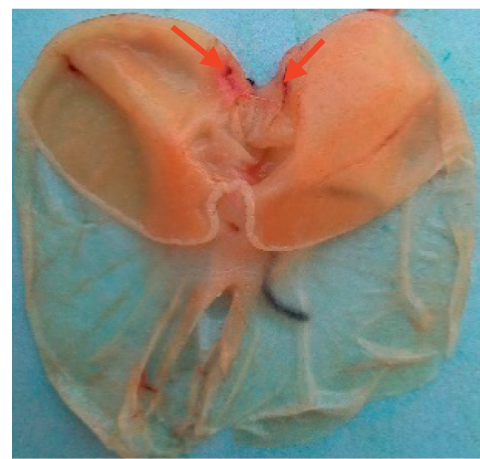

(e)

FIGURE 3: Photograph of stomach ulcerated by pyloric ligation combined with carbachol. (a) Normal control; (b) negative control; (c) $200 \mathrm{mg} / \mathrm{kg}$ of RBAEDM; (d) $400 \mathrm{mg} / \mathrm{kg}$ of RBAEDM; and (e) $50 \mathrm{mg} / \mathrm{kg}$ of verapamil; $\rightarrow$ : indications of gastric lesions.

histamine resulted in an increase in gastric acidity, similarly to those injected with carbachol. RBAEDM administration decreased gastric acidity in animals given histamine and those given carbachol. The reduction in acidity by RBAEDM is accompanied by an increase in $\mathrm{pH}$. The percentage of pepsin hydrolysis increases in rats treated with histamine and those treated with carbachol. These results would suggest that RBAEDM would have acted similarly to ranitidine and verapamil by reducing gastric acid secretion through a mechanism that would involve both the cholinergic and histaminergic pathways. Similar results were obtained by [4] who suggested that the aqueous extract of Eremomastax 
TABLE 6: Effects of RBAEDM on gastric ulcers induced pyloric ligation associated with carbachol.

\begin{tabular}{lccccc}
\hline Treatments & Dose $(\mathrm{mg} / \mathrm{kg})$ & Ulcerated surface $\left(\mathrm{mm}^{2}\right)$ & Ulcer index & Inhibition $(\%)$ & Mucus mass $(\mathrm{mg})$ \\
\hline Normal control & - & - & - & $4.67 \pm 0.28$ & - \\
Negative control & - & $22.60 \pm 1.28$ & $2.58 \pm 0.30^{* * *}$ & 44.75 & $32.67 \pm 2.25$ \\
RBAEDM & 200 & $8.80 \pm 0.80^{* * *}$ & $1.89 \pm 0.10^{* * *}$ & 59.52 & $77.30 \pm 4.11^{* * *}$ \\
RBAEDM & 400 & $7.40 \pm 0.60^{* * *}$ & $2.29 \pm 0.15^{* * *}$ & 50.96 & $84.48 \pm 2.55^{* * *}$ \\
Verapamil & 50 & $12.20 \pm 0.66^{* * *}$ & $39.52 \pm 1.25$ \\
\hline
\end{tabular}

$N=5$ : number of animals per group. Values are expressed as mean \pm standard error of the mean; RBAEDM: root bark aqueous extract of Diospyros mespiliformis; ${ }^{* * *} p<0.001$ : significantly different compared with the negative control.

TABLE 7: Gastric acid hypersecretion induced by pyloric ligation associated with carbachol.

\begin{tabular}{|c|c|c|c|c|c|}
\hline Treatments & Dose $(\mathrm{mg} / \mathrm{kg})$ & VGJ (mL) & $\mathrm{pH}$ & Gastric acidity (mEq/L) & IPA (\%) \\
\hline Normal control & - & - & - & - & - \\
\hline Negative control & - & $3.16 \pm 0.25$ & $1.92 \pm 0.13$ & $30 \pm 3.34$ & - \\
\hline RBAEDM & 200 & $2.60 \pm 0.54$ & $2.09 \pm 0.22$ & $18.40 \pm 0.74^{* *}$ & 32.52 \\
\hline RBAEDM & 400 & $1.88 \pm 0.54$ & $2.47 \pm 0.36$ & $18.00 \pm 0.63^{* *}$ & 34.95 \\
\hline Verapamil & 50 & $1.80 \pm 0.53$ & $3.42 \pm 0.85$ & $21.20 \pm 2.33^{* *}$ & 12.19 \\
\hline
\end{tabular}

$N=5$ : number of animals per group. Values are expressed as mean \pm standard error of the mean; RBAEDM: root bark aqueous extract of Diospyros mespiliformis; VGJ: volume of gastric juice; IPA: inhibition of pepsin activity; ${ }^{* *} p<0.01$ : significantly different compared with the negative control.

TABLE 8: Effect of RBAEDM on some parameters of oxidative stress and nitrites.

\begin{tabular}{|c|c|c|c|c|c|c|}
\hline Treatment & $\begin{array}{l}\text { Dose }(\mathrm{mg} / \\
\mathrm{kg})\end{array}$ & $\begin{array}{l}\mathrm{MDA}(\mu \mathrm{mol} / \mathrm{mg} \\
\text { protein })\end{array}$ & $\begin{array}{l}\text { SOD }(\mathrm{U} / \mathrm{mg} \\
\text { protein) }\end{array}$ & $\begin{array}{c}\mathrm{CAT}\left(\mu \mathrm{mol} \mathrm{H}_{2} \mathrm{O}_{2} / \mathrm{min} / \mathrm{mg}\right. \\
\text { protein })\end{array}$ & $\begin{array}{l}\text { GSH }(\mathrm{mmol} / \mathrm{g} \\
\text { protein) }\end{array}$ & $\begin{array}{l}\text { Nitrites (mol/ } \\
\mathrm{L})\end{array}$ \\
\hline $\begin{array}{l}\text { Normal } \\
\text { control }\end{array}$ & - & $2.03 \pm 0.52$ & $225.55 \pm 4.15$ & $80.09 \pm 5.36$ & $4.23 \pm 5.14$ & $5.01 \pm 0.86$ \\
\hline $\begin{array}{l}\text { Negative } \\
\text { control }\end{array}$ & - & $2.50 \pm 0.10^{\#}$ & $214.00 \pm 6.83$ & $77.10 \pm 4.12$ & $4.59 \pm 4.39$ & $5.56 \pm 0.37$ \\
\hline RBAEDM & 100 & $2.11 \pm 0.68^{*}$ & $224.00 \pm 3.23$ & $79.23 \pm 1.28$ & $5.83 \pm 1.58$ & $8.10 \pm 0.98^{* *}$ \\
\hline RBAEDM & 200 & $2.14 \pm 0.10^{*}$ & $229.60 \pm 2.00$ & $91.27 \pm 1.93^{*}$ & $5.90 \pm 2.05$ & $8.36 \pm 0.62^{* *}$ \\
\hline RBAEDM & 400 & $1.97 \pm 0.92^{* *}$ & $221.80 \pm 4.18$ & $96.30 \pm 5.81^{* *}$ & $5.00 \pm 1.73$ & $9.94 \pm 0.92^{* * *}$ \\
\hline Ranitidine & 50 & $2.06 \pm 0.12^{*}$ & $216.60 \pm 4.70$ & $87.87 \pm 4.35^{*}$ & $5.79 \pm 4.27$ & $5.17 \pm 0.16$ \\
\hline
\end{tabular}

$N=5$ : number of animals per group. Values are expressed as mean \pm standard error of the mean; RBAEDM: root bark aqueous extract of Diospyros mespiliformis; MDA : malondialdehyde; SOD : superoxide dismutase; CAT: catalase; GSH : reduced glutathione; ${ }^{*} p<0.05,{ }^{* *} p<0.01$, and ${ }^{* * *} p<0.001$ : significantly different compared with the negative control; ${ }^{\#} p<0.05$ : significantly different compared with normal control.

TABLE 9: In vitro antioxidant capacity of RBAEDM.

\begin{tabular}{lccc}
\hline Antioxidants & ABTS & DPPH & FRAP \\
\hline$\% \mathrm{I}$ & $77.70 \pm 0.72$ & $68.57 \pm 0.66$ & $58.33 \pm 0.54$ \\
$\mathrm{IC}_{50}(\mu \mathrm{g} / \mathrm{mL})$ & 220 & 494 & 543 \\
\hline
\end{tabular}

$\% I$ : percentage of inhibition; $\mathrm{IC}_{50}$ : inhibitory concentration of $50 \%$.

speciosa contains compounds that would act separately by both pathways or synergically to inhibit gastric acid secretion. The decrease in gastric acidity is thought to be attributed to flavonoids, which decrease histamine secretion by mast cells following inhibition of histidine decarboxylase [39].

Psychological stress, in addition to physical stress such as surgery, leads to oxidative stress in the stomach. Free radicals are normally produced during a normal cellular metabolism. Indeed, the production of free radicals leads to the oxidative stress, which results in the release of MDA. MDA is a classic marker of lipid peroxidation in stomach tissue [1]. SOD, CAT, and GSH are enzymes involved in protecting the stomach from free radical damage [40]. SOD converts the superoxide anion into $\mathrm{H}_{2} \mathrm{O}_{2}$, which is degraded into $\mathrm{H}_{2} \mathrm{O}$ and $\mathrm{O}_{2}$ by catalase [41]. RBAEDM induced a decrease in MDA levels correlated with the increase in activity of antioxidant enzymes such as SOD, CAT, and GSH at different doses of the extract. In this study, a significant decrease in MDA rate was correlated with an increase in SOD and CAT activity. The decrease in lipid peroxidation by the extract would suggest the in vivo antioxidant capacity of RBAEDM. Our results are similar to those obtained by [6] who had shown that the aqueous extract of Emilia praetermissa decreased the MDA level in gastric tissue and therefore decreased lipid peroxidation.

The confirmation of the antioxidant activity in vivo was made by antiradical tests with ABTS, DPPH, and FRAP from RBAEDM. In addition, RBAEDM has the ability to trap the ABTS and DPPH radicals and to reduce iron FRAP. This further confirms the observed in vivo antioxidant capacity of the extract. The $\mathrm{IC}_{50}$ of the aqueous extract of the leaves of Diospyros mespiliformis studied in Benin was $0.58 \mathrm{mg} / \mathrm{mL}$ [15]. This value is higher than that of our extract and shows that the Benin sample is less active than the one studied in this work. This observed activity would be due to the extract's richness in polyphenols and flavonoids, which are powerful free radical scavengers [42]. 
The mucus-bicarbonate barrier is the first line of defense against gastric acid secretion and is under the control of endogenous prostaglandins, which are involved in the protection of the gastric epithelium [16]. The treatment with RBAEDM significantly increased the mucus production in a dose-dependent manner in all three models. The observed action would be due to the presence of flavonoids, which reinforce the defense of the gastric mucosa by direct stimulation of the gastric secretion of mucus; the tannins lead to the precipitation of proteins at the site of the ulcer forming an impermeable barrier against gastric acid. Saponins stimulate mucus-producing factors in the gastric mucosa $[16,43]$.

Nitric oxide (NO) plays a protective role in the gastric mucosa via several mechanisms. It helps in the regulation of gastric acid production and mucus secretion by activating soluble guanylate cyclase, increases mucosal blood flow, binds to $\beta_{3}$ adrenergic receptors [44], and brings oxygen and nutrients into the mucosa while removing harmful waste products. RBAEDM significantly and dose-dependently increased nitrite levels at all the doses. These results suggest that RBAEDM can act by stimulating endothelial cells to release NO, which is gastroprotective. Our results are in line with those obtained by [45] who showed that the methanolic extract of Distemonanthus benthamianus plays its cytoprotective role by increasing NO level in gastric tissues.

\section{Conclusion}

RBAEDM inhibits ulcer formation by stimulating mucus production, enhancing antioxidant status, and inhibiting acid secretion. Antisecretory property could result from its action at the level of cholinergic and histaminergic pathways, and this thanks the presence of pharmacologically active phytoconstituents. The results obtained from this study justify its use in ethnopharmacology for the treatment of gastric ulcers.

\section{Data Availability}

The data used to support the findings of this study are available from the corresponding author upon request.

\section{Conflicts of Interest}

The authors declare that they have no conflicts of interest regarding the publication of this study.

\section{References}

[1] Y. Jia, W. Wei, Y. Xu, and W. Liu, "Activation of p38 MAPK by reactive oxygen species is essential in a rat model of stressinduced gastric mucosal injury," The Journal of Immunology, vol. 179, pp. 7808-7819, 2020.

[2] S. Levenstein, "Stress and peptic ulcer: life beyond helicobacter," British Medical Journal, vol. 316, pp. 538-549, 2015.

[3] D.-Q. Zhao, H. Xue, and H.-J. Sun, "Nervous mechanisms of restraint water-immersion stress-induced gastric mucosal lesion," World Journal of Gastroenterology, vol. 26, no. 20, pp. 2533-2549, 2020.
[4] A. P. Amang, P. V. Tan, E. Nkwengoua, and B. Nyasse, "Antisecretory action of the extract of the aerial parts of Eremomastax speciosa (Acanthaceae) occurs through antihistaminic and anticholinergic pathways," Advances in Pharmacological Sciences, vol. 2014, Article ID 323470, 10 pages, 2014.

[5] M. S. Dayane, L. R. M. Jose, F. F. Iziara, and R. O. Danillo, "The gastroprotective effect of Memora nodosa roots against experimental gastric ulcer in mice," Annals of the Brazilian Academy of Sciences, vol. 88, no. 3, pp. 1819-1828, 2016.

[6] O. L. Ndji, A. P. Amang, C. Mezui, Z. E. Nkwengoua, and P. V. Tan, "Gastric ulcer protective and antioxidant activity of the leaf ethanol extract of Emilia praetermissa Milne-Redh (Asteraceae) in rats," Journal of International Research in Medical and Pharmaceutical Sciences, vol. 6, no. 2, pp. 98-107, 2016.

[7] J. M. Kirsch and C. Hirsch-Reilly, "Peptic ulcer disease," in Acute Care General SurgeryVol. 11, Gewerbestrasse, Cham, Switzerland, 2017.

[8] H. Zatorski, "Pathophysiology and risk factors in peptic ulcer disease," in Introduction to Gastrointestinal Diseasesvol. 11, Cham, Switzerland, Gewerbestrasse, 2017.

[9] M. Madigan and B. Zuckerbraum, "Therapeutic potential of the nitrite-generated NO pathway in vascular dysfunction," Frontiers in Immunology, vol. 7, no. 174, pp. 1-9, 2013.

[10] A. Bouyahia and Y. Abboud, Evaluation de l'activité NOsynthase dans le tissu gastrique de souris ulcérées, Université A MIRA-Bejaia, Bejaia, Algeria, 2018.

[11] L. Kuna, J. Jakab, R. Smolic, N. Raguz-Lucic, A. Vcev, and M. Smolic, "Peptic ulcer disease: a brief review of conventional therapy and herbal treatment options," Journal of Clinical Medicine, vol. 8, no. 179, pp. 1-19, 2019.

[12] Prota, "Diospyros mespiliformis," PlanteUse, pp. 1-10, 2017.

[13] B. Adzu, S. Amos, S. Dzarma, I. Muazzam, and K. S. Gamaniel, "Pharmacological evidence favouring the folkloric use of Diospyros mespiliformis Hochst in the relief of pain and fever," Journal of Ethnopharmacology, vol. 82, no. 23, pp. 191-195, 2002.

[14] B. A. Lajubutu, R. J. Pinney, M. F. Roberts, H. A. Odelola, and B. A. Oso, "Antibacterial activity of diosquinone and plumbagin from the root of Diospyros mespiliformis (Hostch) (Ebenaceae)," Phytotherapy Research, vol. 9, no. 5, pp. 346-350, 1995.

[15] M. Yovo, S. O. Dedome, P. Sessou, and G. A. Alitonou, "Phytochimical studies and biological activities of extract from two medicinal plants used in Benin to treat skin infection sand septicemies," International Journal of Innovation and Applied Studies, vol. 28, no. 2, pp. 507-514, 2020.

[16] A. P. Amang, P. Bouvourne, C. Mezui, G. T. Siwe, M. T. Kuissu, and P. V Tan, "Gastro-protective activity of the leaves aqueous extract of Diospiros mespiliformis on gastric ulcers in Swiss mice," International Journal of Pharmacognosy, vol. 7, no. 2, pp. 44-51, 2020.

[17] V. L. Singleton and J. A. Rossi, "Colorimetry of total phenolics with phosphomolybdic-phosphotungstic acid reagents," American Journal of Technology and Viticulture, vol. 16, pp. 144-153, 1999.

[18] C. Chang, M. Yang, H. Wen, and J. Chern, "Estimation of total flavonoid content in propolis by two complementary colorimetric methods," Journal of Food and Drug Analysis, vol. 10, pp. 178-182, 2002.

[19] M. Govindappa, S. Naga-Sravya, M. N. Poojashri, T. S. Sadananda, and C. P. Chandrappa, "Antimicrobial, antioxidant and in vitro anti-inflammatory activity of ethanol extract and active phytochemical screening of Wedelia 
trilobata (L.) hitchc," Journal of Pharmacognosy and Phytochemistry, vol. 3, no. 3, pp. 43-51, 2011.

[20] J. H. Brunner, "Direct spectrophotometric determination of saponin," Analytical Chemistry, vol. 34, pp. 1314-1326, 1984.

[21] J. Lee, C. Rennaker, and R. E. Wrolstad, "Correlation of two anthocyanin quantification methods: HPLC and Spectrophotometric methods," Food Chemistry, vol. 110, no. 3, pp. 782-786, 2008.

[22] J. P. Shay, S. A. Komarov, S. S. Fels, D. Meranze, M. Grunstein, and H. Simpler, "A simple method for the uniform production of gastric ulceration in the rat," Journal of Gastroenterology, vol. 5, pp. 43-61, 1945.

[23] P. V. Tan, G. N. Nditafon, M. P. Yewah, J. F. Ayafor, and T. Dimo, "Eremomastax speciosa: effect on the leaf aqueous extract on ulcer formation and gastric secretion in rats," Journal of Ethnopharmacology, vol. 54, no. 3, pp. 139-142, 1996.

[24] R. J. Henry, D. C. Canon, and J. W. Winkelman, Clinical Chemistry, Principles and Techniques, Harper \& R, Berlin, Germany, 1974.

[25] K. M. Wilbur, F. Bernheim, and O. W. Shapiro, "Determination of lipid peroxidation," Archives of Biochemistry and Biophysics, vol. 24, pp. 305-310, 1949.

[26] H. P. Misra and I. Fridovich, "The role of superoxide anion in the autoxidation of epinephrine and a simple assay for superoxide dismutase," Journal of Biological Chemistry, vol. 247, no. 10 , pp. 3170-3175, 1972.

[27] A. K. Sinha, "Colorimetric assay of catalase," Analytical Biochemistry, vol. 47, no. 2, pp. 389-394, 1972.

[28] G. L. Ellman, "Tissue sulfhydryl groups," Archives of Biochemistry and Biophysics, vol. 82, no. 1, pp. 70-77, 1959.

[29] A. Zainul, B. Tavamani, K. Ahmad, H. Maizatul, M. Norhafizah, and A. Zuraini, "Mechanism(s) of action underlying the gastroprotective effect of ethyl acetate fraction obtained from the crude methanolic leaves extract of Muntingia calabura," African Journal of Traditional, Complementary and Alternative Medicines, vol. 16, pp. 1-17, 2016.

[30] R. Re, N. Pellegrini, A Proteggente, A. Pannala, M Yang, and C Rice-Evans, "Antioxidant activity applying an improved ABTS radical cation decolorization assay," Free Radical Biology and Medicine, vol. 26, no. 9, pp. 1231-1237, 1999.

[31] T. Sun, J. Tang, and J. R. Powers, "Effect of pectolytic enzyme preparations on the phenolic composition and antioxidant activity of Asparagus juice," Journal of Agricultural and Food Chemistry, vol. 113, pp. 964-969, 2005.

[32] I. F. F. Benzie and J. J. Strain, "The ferric reducing ability of plasma (FRAP) as a measure of "antioxidant power": the FRAP assay," Analytical Biochemistry, vol. 239, no. 1, pp. 70-76, 1996.

[33] C. A. Eze, D. C. Anyogu, I. C. Nwogu, and S. S. Adamu, "Antiulcer activities of oil extract of Balanites aegyptiaca seed in Guinea pigs," Journal of Medicinal Plants Research, vol. 7, no. 34, pp. 2533-2537, 2013.

[34] S. T. Landa, K. R. Dumon, and D. T. Dempsey, Anatomy and Physiology of the Stomach and Pylorus, pp. 49-64, the SAGES Manual of Foregut Surgery, Philadelphia, USA, 2019.

[35] M. Hussain, I. Hazarika, and A. Das, "Pylorus ligation induced gastric ulcer protection by Sesamum indicum ethanolic seed extract," Research \& Reviews: A Journal of Pharmaceutical Science, vol. 6, no. 3, pp. 42-49, 2015.

[36] C. Mezui, A. P. Amang, C. Nkenfou, and Z. Sando, "Antiulcer and antioxidant activities of the leaf aqueous extract of Corchorus olitorius (tiliaceae) in rats," International Journal of Phytopharmacology, vol. 7, no. 1, pp. 17-28, 2016.
[37] O. W. Menizibeya, Gastrointestinal Physiology, Vol. 11, Gewerbestrasse, , Cham, Switzerland, 2018.

[38] S. K. Sahoo, H. B. Sahoo, D. Priyadarshini, G. Soundarya, C. K. Kumar, and K. U Rani, "Antiulcer activity of ethanolic extract of Salvadora indica (W.) leaves on albino rats," Journal of Clinical and Diagnostic Research: Journal of Clinical and Diagnostic Research, vol. 10, no. 9, pp. FF07-10, 2016.

[39] F. Borrelli and A. A. Izzo, "The plant kingdom as a source of anti-ulcer remedies," Phytotherapy Research, vol. 14, no. 8, pp. 581-591, 2000.

[40] A. Bhattacharyya, R. Chattopadhyay, S. Mitra, and S. E. Crowe, "Oxidative stress: an essential factor in the pathogenesis of gastrointestinal mucosal diseases," Physiological Reviews, vol. 94, no. 2, pp. 329-354, 2014.

[41] P. A. Amang, P. V. Tan, S. A. Patamaken, and M. N. Mefe, "Cytoprotective and antioxidant effects of the methanol extract of Eremomastax speciosa in rats," African Journal of Traditional, Complementary, and Alternative Medicines: AJTCAM, vol. 11, no. 1, pp. 165-171, 2014.

[42] C. Mezui, C. Nkenfou, A. P. Amang, and G. Ndji, "Gastroprotective, antioxidant and antibacterial properties of the aqueous root bark extract of Cassia arereh del. (Caesalpiniaceae) in a wistar rat model," Journal of Advances in Biology \& Biotechnology, vol. 12, no. 4, pp. 1-13, 2017.

[43] A. P. Amang, V. L. Vandi, C. Mezui, T. G. Siwe, T. M. Kuissu, and P. V Tan, "Cytoprotective effects of the leaves aqueous extract of Combretum glutinosum (Combretaceae) on gastric ulcers in mice," International Research Journal of Biological Sciences, vol. 9, no. 2, pp. 6-11, 2020.

[44] M. A. Morsy, G. H. Heeba, S. A. Abdelwahab, and R. R. Rofaeil, "Protective effects of nebivolol against cold restraint stress-induced gastric ulcer in rats: role of $\mathrm{NO}, \mathrm{HO}-$ 1, and COX-1,2," Nitric Oxide, vol. 27, no. 2, pp. 117-122, 2012.

[45] V. M. Matah Marte, G. Ateufack, M. Mbiantcha et al., "Methanolic extract of Distemonanthus benthamianus (caesalpiniaceae) stem bark suppresses ethanol/indomethacininduced chronic gastric injury in rats," Gastroenterology Research and Practice, vol. 2020, pp. 1-14, 2020. 